\title{
The hypothalamus and periaqueductal gray are the sources of dopamine fibers in the paraventricular nucleus of the thalamus in the rat
}

\author{
Sa $\mathrm{Li}^{1,2}$, Yuxiu Shi ${ }^{1 *}$ and Gilbert J. Kirouac ${ }^{2,3}$ \\ 1 PTSD Laboratory, Department of Histology and Embryology, Institute of Pathology and Pathophysiology, China Medical University, Shenyang, China \\ ${ }^{2}$ Department of Oral Biology, Faculty of Dentistry, University of Manitoba, Winnipeg, MB, Canada \\ ${ }^{3}$ Department of Psychiatry, Faculty of Medicine, University of Manitoba, Winnipeg, MB, Canada
}

Edited by:

Kathleen S. Rockland, Boston

University School Medicine, USA

Reviewed by:

Ariel Y. Deutch, Vanderbilt

University Medical Center, USA

Carmen Cavada, Universidad

Autonoma de Madrid, Spain

${ }^{*}$ Correspondence:

Yuxiu Shi, PTSD Laboratory,

Department of Histology and

Embryology, Institute of Pathology

and Pathophysiology, China Medical University, Basic Medical Sciences

Building C, Room 112, 77 PUHE

Road, Shenyang 110013, China

e-mail: shiyuxiu@163.com
The paraventricular nucleus of the thalamus (PVT) sends a very dense projection to the nucleus accumbens. This area of the striatum plays a key role in motivation and recent experimental evidence indicates that the PVT may have a similar function. It is well known that a dopaminergic projection from the ventral tegmental area (VTA) to the nucleus accumbens is a key regulator of motivation and reward-related behavior. Dopamine (DA) fibers have also been localized in the PVT but the source of these fibers in the rat has not been unequivocally identified. The present study was done to re-examine this question. Small iontophoretic injections of cholera toxin B (CTb) were made in the PVT to retrogradely label tyrosine hydroxylase $(\mathrm{TH})$ neurons. Neurons that were double-labeled for TH/CTb were found scattered in DA cell groups of the hypothalamus (ventrorostral A10, A11, A13, A15 DA cell groups) and the midbrain (dorsocaudal A10 embedded in the periaqueductal gray). In contrast, double-labeled neurons were absent in the retrorubral field (A8), substantia nigra (A9) and VTA (A10) of the midbrain. We conclude that DA fibers in the PVT do not originate from VTA but from a heterogeneous population of DA neurons located in the hypothalamus and periaqueductal gray.

Keywords: paraventricular nucleus, dopamine, ventral tegmental area, hypothalamus, thalamus

\section{INTRODUCTION}

The paraventricular nucleus of the thalamus (PVT) is a member of a group of midline and intralaminar thalamic nuclei that are believed to be involved in cognition, attention and arousal (Groenewegen and Berendse, 1994; Van der Werf et al., 2002). Each member of this group has circumscribed projections to unique regions of the cerebral cortex and the striatum. This anatomical arrangement has led to the view that different members of the midline and intralaminar nuclei are part of functionally distinct circuits with specialized functions (Groenewegen and Berendse, 1994; Van der Werf et al., 2002). The PVT is of special interest because of its dense projection to the nucleus accumbens of the ventral striatum (Li and Kirouac, 2008; Vertes and Hoover, 2008),

\footnotetext{
Abbreviations: 3V, 3rd ventricle; A8, retrorubral dopamine group; A9, substantia nigra; A10, ventral tegmental area; A10dc, periaqueductal gray matter; A10vr, A10 ventrorostral dopamine group; A11, A11 dopamine group; A13, A13 dopamine group; Aq, aqueduct; $\mathrm{CM}$, central medial thalamic nucleus; $\mathrm{cp}$, cerebral peduncle; DA, dopamine; f, fornix; fr, fasciculus retroflexus; $\mathrm{Hb}$, habenular; IMD, intermediodorsal thalamic nucleus; MD, mediodorsal thalamic nucleus; ml, medial lemniscus; mt, mammillothalamic tract; opt, optic tract; PT, paratenial thalamic nucleus; PVT, paraventricular thalamic nucleus; Rt, reticular thalamic nucleus; sm, stria medullaris of the thalamus; VTA, ventral tegmental area; xscp, decussation sup cereballar ped; ZI, zona incerta.
}

an area of the brain closely linked to the regulation of reward and motivation (Nicola, 2007; Humphries and Prescott, 2010). In addition, the PVT projects to all the major sources of inputs to the nucleus accumbens including the medial prefrontal cortex (ventral prelimbic and infralimbic cortices), ventral subiculum of the hippocampus, and the basolateral nucleus of the amygdala (Groenewegen et al., 1987; Berendse and Groenewegen, 1990; Berendse et al., 1992; Brog et al., 1993; Wright and Groenewegen, 1995; Wright et al., 1996).

Recent experimental evidence supports a role for the PVT in drug seeking and reward-related behaviors (Martin-Fardon and Boutrel, 2012; James and Dayas, 2013; Matzeu et al., 2014). For instance, an increase in cFos has been observed in the PVT following the re-exposure of rodents to the context or cues associated with cocaine administrations (Brown et al., 1992; Franklin and Druhan, 2000; James et al., 2011). Inactivation of the PVT was also reported to attenuate cocaine-prime induced reinstatement of self-administration as well as cocaine induced conditioned place preference (James et al., 2010; Browning et al., 2014). Similarly, an increase in cFos was found in the PVT following contextand cue-induced reinstatement of alcohol seeking in rodents (Wedzony et al., 2003; Dayas et al., 2008; Perry and Mcnally, 2013) while inactivation of the PVT was reported to attenuate context-induced reinstatement of ethanol (Hamlin et al., 2009; 
Marchant et al., 2010). Finally, evidence in support of a role for the PVT in food reward is provided by studies showing an increase in cFos in the PVT following exposure to cues that predict a sucrose reward (Igelstrom et al., 2010; Flagel et al., 2011).

Dopamine (DA) neurons in the ventral tegmental area (VTA) and their projections to the nucleus accumbens have been implicated in reward and motivation (Pennartz et al., 1994; Ikemoto and Panksepp, 1999; Schultz, 2000; Salamone et al., 2005; Ikemoto, 2007). The PVT has also been shown to contain fibers that stain for tyrosine hydroxylase $(\mathrm{TH})$, the rate limiting enzyme involves in the synthesis of DA (Takada et al., 1990; Otake and Ruggiero, 1995). In addition, the PVT contains fibers immunopositive for DA as well as the DA transporter indicating that some of the $\mathrm{TH}$ fibers in that area of the thalamus are dopaminergic fibers (Groenewegen, 1988; García-Cabezas et al., 2009). Indeed, the PVT was reported to contain a more notable plexus of immunopositive DA fibers than other dorsal midline thalamic nuclei (Groenewegen, 1988). Consequently, it is possible that the PVT is part of the neural circuitry that mediates DA's motivational functions (VTA-PVT-nucleus accumbens). However, the two studies that have examined the source of DA fibers in the PVT in the rat have come to different conclusions with one study finding evidence that the VTA provided the input (Takada et al., 1990) while the other reporting that the hypothalamus was the source (Otake and Ruggiero, 1995). Part of this discrepancy may be due to differences in the placement of retrograde tracers in the midline thalamus. The interpretation of these two studies is also limited by the fact that the location of the injections is not clearly shown.

It is important that the sources of DA fibers in the PVT be unequivocally identified to better understand the potential involvement of the PVT in DA-mediated behaviors. In this study, iontophoretic injections of the retrograde tracer cholera toxin $\mathrm{B}$ (CTb) were made in the anterior and posterior segments of the PVT (referred to as the aPVT and pPVT, respectively). The location of $\mathrm{CTb}$ and $\mathrm{TH}$ double-labeled cells were assessed in areas of the brain known to contain DA neurons.

\section{MATERIALS AND METHODS ANIMALS}

Male Sprague-Dawley rats weighing $210 \pm 10 \mathrm{~g}$ ( $n=8$; University of Manitoba vivarium) were used for this study. Animals were housed on a 12/12-h light/dark cycle with food and water freely available. The experimental procedures were in compliance with the Canadian Council on Animal Care and the experimental protocol was approved by Research Ethics Review Board of the University of Manitoba.

\section{RETROGRADE TRACING EXPERIMENT}

Rats were anesthetized with a mixture of ketamine (Ketalean Hydrochloride $100 \mathrm{mg} / \mathrm{ml}, 100 \mathrm{mg} / \mathrm{kg}$, i.p.) and xylazine (Rompun $20 \mathrm{mg} / \mathrm{ml}, 10 \mathrm{mg} / \mathrm{kg}$, i.p.) and given supplementary doses if necessary. Animals were placed in a Stoelting stereotaxic frame and a hand drill was used to expose the brain surface above the target sites. Iontophoretic injections of $0.5 \% \mathrm{CTb}$ (List Biologicals, Campbell, CA, USA), which was dissolved in
$0.01 \mathrm{M}$ phosphate buffer ( $\mathrm{PB}$; $\mathrm{pH} 7.4$ ), were done by applying a positive current of $1.0-2.5 \mu \mathrm{A}(200 \mathrm{~ms}$ pulses at $2 \mathrm{~Hz}$ for $15 \mathrm{~min}$ ) through a chlorinated silver wire placed in a glass pipette (approximately $7 \mu \mathrm{m}$ diameter tip). The coordinates used for injecting CTb were as follows: aPVT at $1.5 \mathrm{~mm}$ posterior, $1.0 \mathrm{~mm}$ lateral, $5.0 \mathrm{~mm}$ ventral, $10^{\circ}$ angle toward the middle; and pPVT at $3.0 \mathrm{~mm}$ posterior, $0.7 \mathrm{~mm}$ lateral, $5.0 \mathrm{~mm}$ ventral, $10^{\circ}$ angle toward the middle (all coordinates are relative to bregma and the dural surface of the brain with the incisor bar at $3.3 \mathrm{~mm}$ below intra-aural line). After the scalp incisions were sutured, rats were returned to their home cages for recovery. The analgesic Carprofen $(5 \mathrm{mg} / \mathrm{kg}$, s.c.) was given after surgery and $12 \mathrm{~h}$ later. After a 10- to 12-day postoperative survival, rats were deeply anesthetized with $10 \%$ chloral hydrate and transcardially perfused with $150 \mathrm{ml}$ heparinized saline followed by $400-500 \mathrm{ml}$ icecold $4 \%$ paraformaldehyde in $0.1 \mathrm{M} \mathrm{PB}$ ( $\mathrm{pH} 7.4$ ). The brains were removed, post-fixed in the same fixative for $1-2 \mathrm{~h}$, and cryoprotected in graded sucrose concentrations (10 and 20\% w/v) over 2 days at $4^{\circ} \mathrm{C}$. Sections of the brain were taken at $50 \mu \mathrm{m}$ and placed in $0.1 \mathrm{M}$ phosphate-buffered saline (PBS; pH 7.4) with $0.1 \%$ sodium azide and stored at $4{ }^{\circ} \mathrm{C}$ until the time of the immunoreaction.

\section{IMMUNOHISTOCHEMISTRY}

All immunohistochemical reactions were carried out at room temperature on free-floating sections. Primary and secondary antibodies were diluted in blocking solution containing $0.1 \%$ sodium azide, $5 \%$ normal donkey serum, and $0.3 \%$ Triton X-100 in PBS. Every 4th sections were pre-incubated in the blocking solution for $1 \mathrm{~h}$ at room temperature, and then transferred to a cocktail of primary antibodies containing goat anti-CTb (1:10,000; List Biologicals; cat. \#703, lot 7032H) and monoclonal mouse anti-tyrosine hydroxylase (TH; 1:100,000; Sigma; cat. \#T2928; clone TH-16) and incubated overnight. After 3 rinses, sections were transferred into a biotinylated donkey anti-goat antibody solution (1:500; Jackson Immunoresearch, West Grove, PA, USA) for $1 \mathrm{~h}$. Sections were rinsed again and then exposed to an avidin-biotin complex (Elite ABC Kit; Vector Laboratories, Burlingame, CA, USA) for $60 \mathrm{~min}$. After a few more rinses, the tissue was reacted for 3-5 $\mathrm{min}$ with diaminobenzidine (DAB) with nickel intensification (Vector DAB Kit) to produce black $\mathrm{CTb}$ labeling. The brain sections were then rinsed in PBS and incubated in biotinylated donkey anti-mouse antiserum (1:500; Jackson Immunoresearch) for $1 \mathrm{~h}$. Sections were rinsed and incubated in $\mathrm{ABC}$ for $60 \mathrm{~min}$, rinsed, and reacted for 1-2 min with $\mathrm{DAB}$ without nickel intensification to produce brown $\mathrm{TH}$ cell labeling. The DAB reaction was terminated by rinsing in PBS before the sections were mounted onto gelatin coated slides and coverslipped.

The antibodies used for these experiments have been previously characterized. The $\mathrm{CTb}$ antibody does not bind to any endogenous epitopes in the rat brain (Luppi et al., 1990). The monoclonal $\mathrm{TH}$ antibody was produced from the TH-16 hybridoma and purified rat $\mathrm{TH}$ was used as the immunogen to produce this antibody. This $\mathrm{TH}$ antibody recognizes a specific epitope present on the $\mathrm{N}$-terminal region of rodent $\mathrm{TH}$ (technical information provided by manufacturer). Furthermore, 
this antibody produced the same staining pattern in the rat brain as previously reported (Lindvall et al., 1983; Hökfelt et al., 1984) and negative controls (leaving out the primary antibody) were used to establish specificity of the TH staining.

\section{ANALYSIS}

Brain sections were examined with an Olympus BX51 microscope and only the cases with injections that resulted in a dense core of CTb confined to the PVT were used for the present study. Since the purpose of the present study was to examine the source of DA innervation to the PVT, only areas of the hypothalamus and brainstem containing the DA cell groups were examined for the presence of $\mathrm{TH} / \mathrm{CTb}$ double-labeled neurons. Neurons expressing DA form a continuum that extends from the periaqueductal gray to the preoptic area of the hypothalamus. This continuum has been subdivided into different groups based on earlier classification (Dahlstroem and Fuxe, 1964; Léger et al., 2010): A8 (retrorubral field of the caudal mesencephalic reticular formation); A9 (substantia nigra pars compacta and lateralis); A10 (ventral tegmental area); A10 dorsocaudal (A10dc, periaqueductal gray matter); A10 ventrorostral (A10vr, cells anterior to the VTA in the supramammillary regon); A11 (from the rostral portion of the periaqueductal gray to the posterior hypothalamus adjacent to the mammillothalamic tract); A12 (arcuate nucleus); A13 (zona incerta region); A14 (along the third ventricle in the rostral hypothalamus including the posterior part of the paraventricular hypothalamamic nucleus); and the A15 (anterior hypothalamus region above the optic chiasm/suproptic nucleus and ventral to the anterior commissure). Every section was examined at high magnification for the presence of $\mathrm{CTb}$ granules in $\mathrm{TH}$ positive neurons. A figure of a representative case showing $\mathrm{TH}$ and $\mathrm{TH} / \mathrm{CTb}$-double labeled neurons was produced using Adobe Illustrator (CS4) by digitally superimposing photographed images of the areas in question with digital drawings modified from a stereotaxic atlas (Paxinos and Watson, 2009). Examples of CTb- and TH-positive neurons were photographed using a digital camera (Spot RT Slicer; Diagnostic Instruments, Sterling Heights, MI) mounted on the microscope. The calibration bars were inserted with the Spot software (version 3.2; Diagnostic Instruments) and images were transferred to Adobe Photoshop (CS4) to optimize light and contrast levels.

\section{RESULTS \\ INJECTIONS}

Data on the sources of DA fibers to the PVT were obtained from cases that had $\mathrm{CTb}$ injections that were almost entirely restricted to either the aPVT $(n=4$; Figure 1A) or pPVT ( $n$ $=4$; Figure 1B). Figure 2 shows the location of the dense $\mathrm{CTb}$ core of each injection in relation to the PVT and other midline thalamic nuclei. In most cases, the dense core (area likely to result in retrograde transport) covered a large part of the PVT with a very minor involvement of the mediodorsal, paratenial, centromedial, or intermediodorsal nuclei. The PVT extends the entire length of the thalamus and the extent of the injection core was restricted to only a portion of the aPVT or pPVT. This may produce a gross underestimation of DA neurons
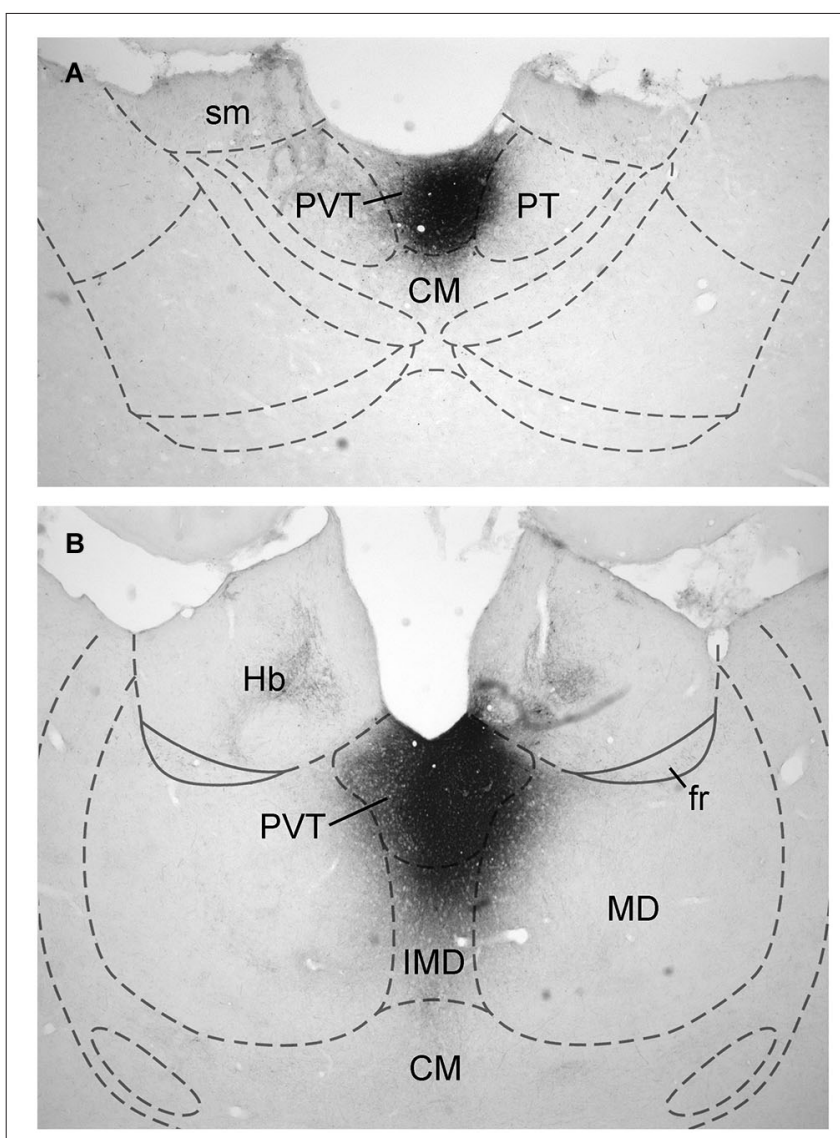

FIGURE 1 | Examples of injection sites. Digital image examples of cholera toxin $\mathbf{B}$ injection in the anterior $(\mathbf{A})$ and posterior $(\mathbf{B})$ aspects of the paraventricular nucleus of the thalamus. For abbreviations, see list.

likely to supply afferents to the PVT. The approach of using small injections was necessary since other tracing studies have shown that the mediodorsal nucleus and habenular complex located immediately adjacent to the PVT are innervated by DA neurons in the VTA (Groenewegen, 1988; Gruber et al., 2007). Large injections of $\mathrm{CTb}$ in the dorsal thalamus could have led to incorrect conclusions about the sources of DA afferents to the PVT.

\section{PATTERN OF RETROGRADE LABELING}

A large number of CTb-labeled neurons were found in many regions of the hypothalamus as previously reported (Otake and Ruggiero, 1995; Li and Kirouac, 2012). Figures 3, 4 show the location of CTb- and $\mathrm{TH}$-labeled neurons in areas of the hypothalamus and midbrain, respectively, following the analysis of an injection of CTb in the pPVT. Based on the large number of CTb-labeled cells in the hypothalamus, it is clear that the injection sites used for the present paper were adequate to examine the sources of the DA fibers in the PVT. Consistent with previous papers, the periaqueductal gray, dorsomedial nucleus of the hypothalamus, and the reticular nucleus of the thalamus were found to be the major sources of inputs to the pPVT (Otake and Ruggiero, 1995; 
A

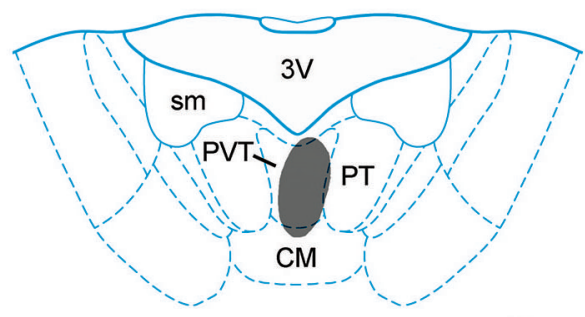

$-1.32 \mathrm{~mm}$

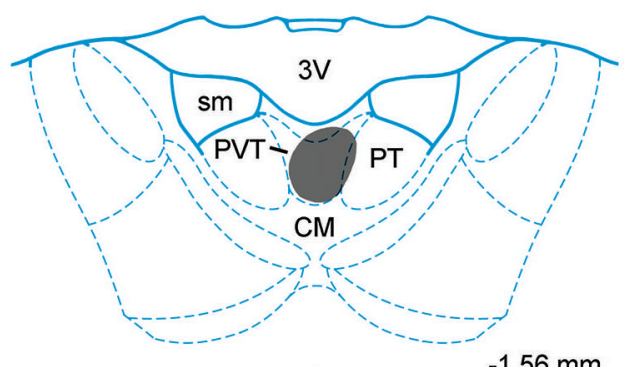

$-1.56 \mathrm{~mm}$

B

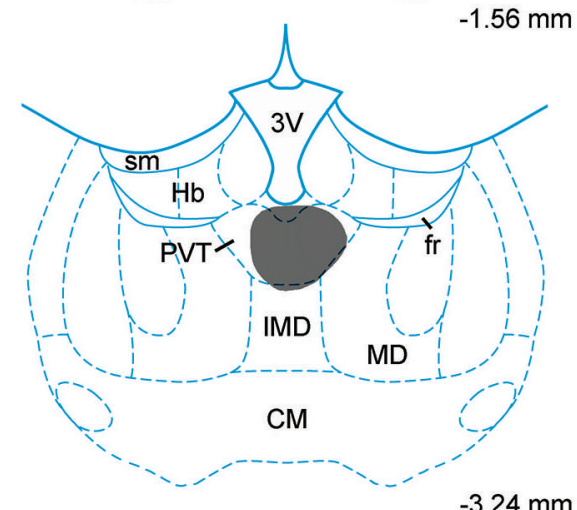

$-3.24 \mathrm{~mm}$

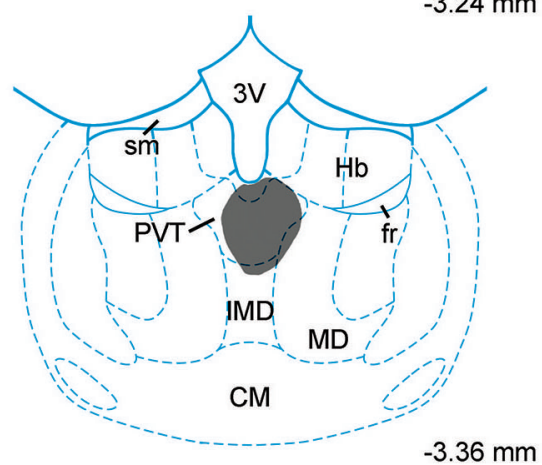

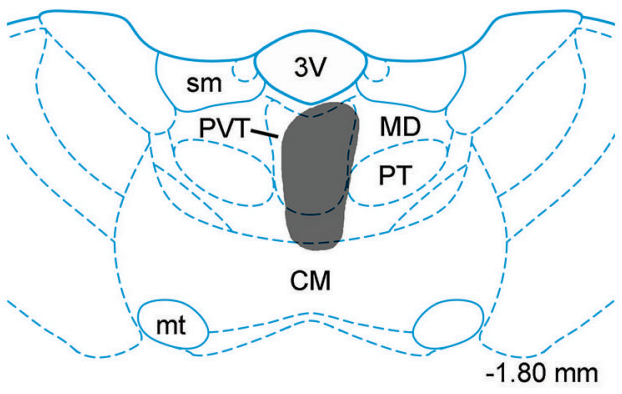

$-1.80 \mathrm{~mm}$

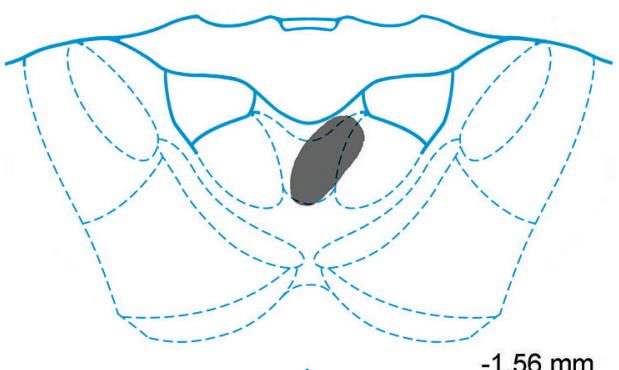

$-1.56 \mathrm{~mm}$

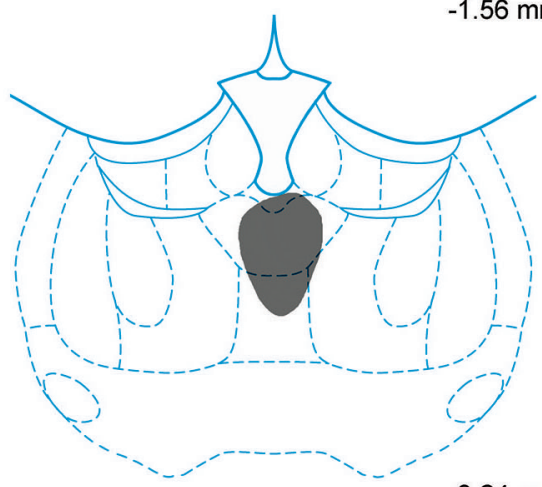

$-3.24 \mathrm{~mm}$

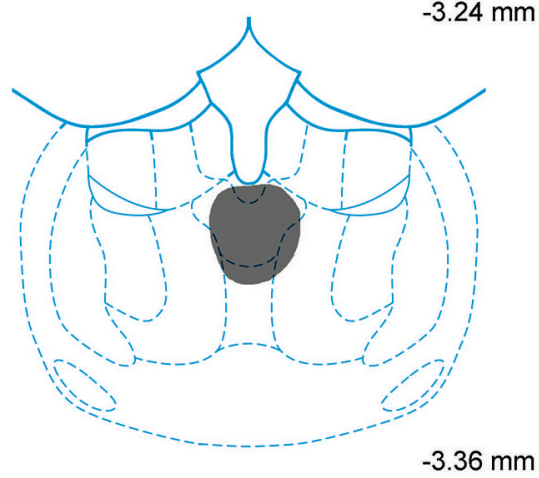

FIGURE 2 | Injection sites. Schematic representation of cholera toxin B injections in the anterior (A) and posterior (B) aspects of the paraventricular nucleus of the thalamus. Numbers on the bottom of each drawing represent the distance from bregma. For abbreviations, see list.

Li and Kirouac, 2012). The distribution of TH-labeled neurons was consistent with previous descriptions of the DA cell groups in the hypothalamus and midbrain (Dahlstroem and Fuxe, 1964; Léger et al., 2010). After close examination of all the cases, we found that the majority of TH/CTb doublelabeled neurons were located in the A15 (Figures 3A-C), A13 (Figures 3E,F, 5A-C), and A11 cell groups (Figures 3G,H, 4A, 5D-G). In addition, TH/CTb double-labeled neurons were found scattered in the zona incerta (Figures 3E,F), A12 group (Figure 3E), perifornical hypothalamus (Figures 3D-F), A10vr area (Figures $3 \mathbf{H}, \mathbf{4 A}, \mathbf{5 H}-\mathbf{J}$ ) and periaqueductal gray (A10dc; Figure 4D). Of note, double-labeled neurons were not found in the VTA (A10), substantia nigra (A9), and the retrorubral field (A8) as shown in Figures 4B,C. Consistent with the fact that the $\mathrm{CTb}$ injections involved predominately one side of the PVT, in all cases double-labeled neurons were found bilaterally 

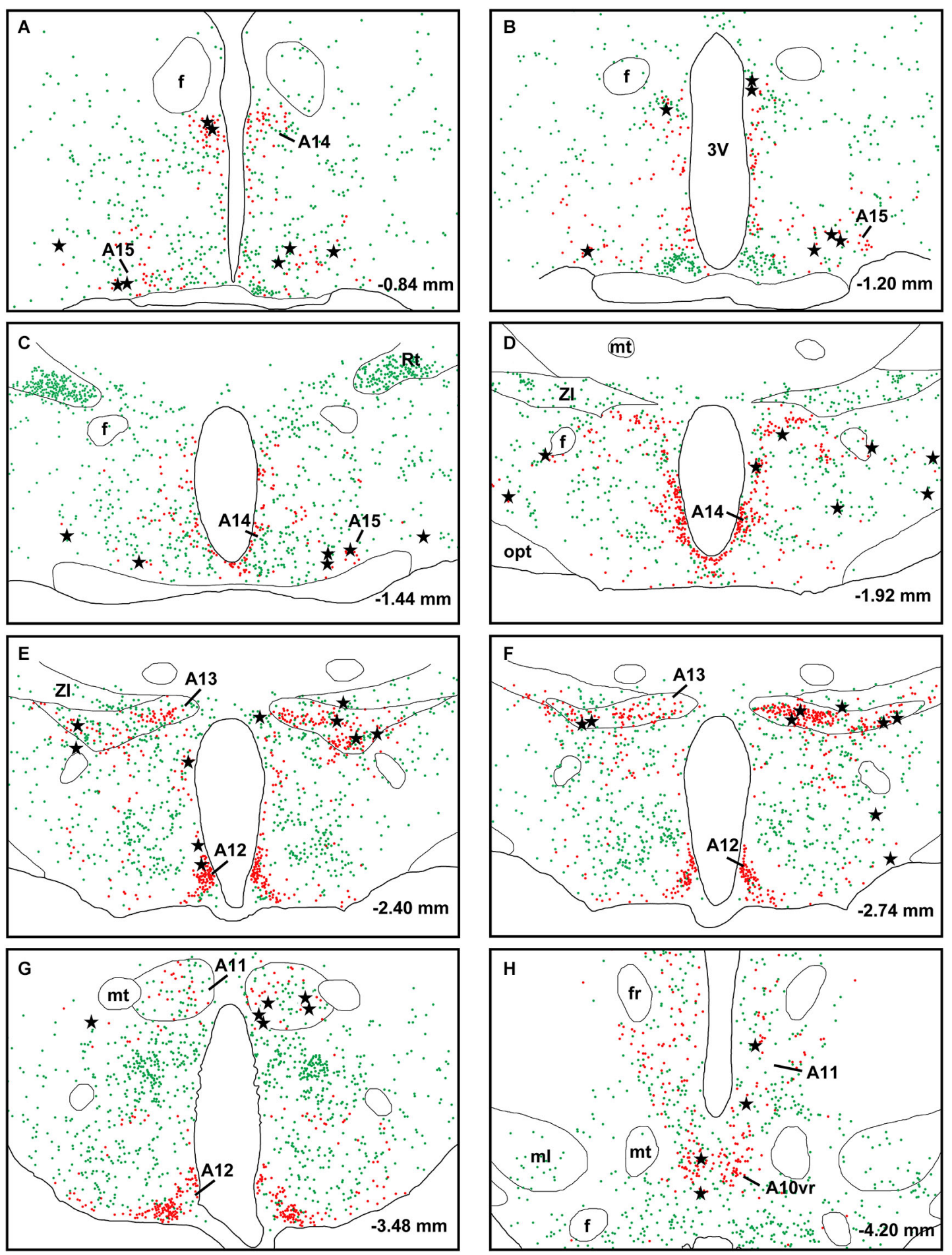

FIGURE 3 | Retrograde labeling in the hypothalamus. The rostrocaudal sequence of sections are labeled from $(\mathbf{A}-\mathbf{H})$. Drawings of coronal sections with major dopamine cell groups illustrating cells that were immunopositive for tyrosine hydroxylase ( $\mathrm{TH}$; red) and cholera toxin B (CTb; green) after an

injection of CTb into the posterior part of the paraventricular nucleus of the thalamus. The location of TH/CTb double-labeled neurons are shown as black stars. Numbers on the bottom right of each drawing represent the distance from bregma. For abbreviations, see list.

with an ipsilateral predominance in both the hypothalamus and midbrain (Figures 3, 4). Although the aPVT injections resulted in fewer double-labeled neurons, there were no qualitative

differences on the pattern of TH/CTb double-labeled neurons between injections in the aPVT and pPVT. Attempts to quantify the proportion of $\mathrm{TH}$-positive neurons that were $\mathrm{CTb}$-positive 

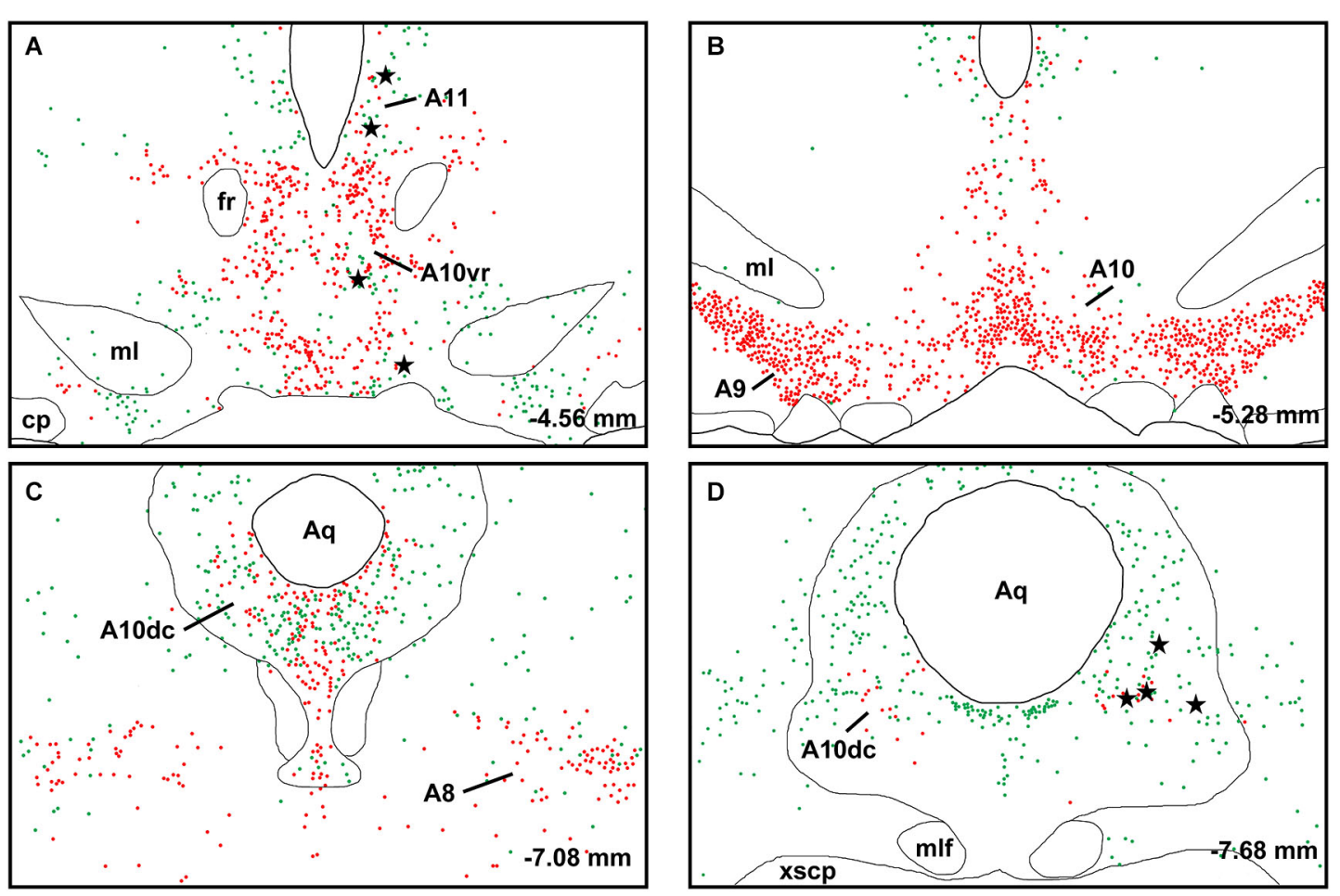

FIGURE 4 | Retrograde labeling in midbrain. The rostrocaudal sequence of sections are labeled from (A-D). Drawings of coronal sections with major dopamine cell groups illustrating cells that were immunopositive for tyrosine hydroxylase ( $\mathrm{TH}$; red) and cholera toxin $\mathrm{B}$ (CTb; green) after an injection of

$\mathrm{CTb}$ into the posterior part of the paraventricular nucleus of the thalamus. The location of TH/CTb double-labeled neurons are shown as black stars. Numbers on the bottom right of each drawing represent the distance from bregma. For abbreviations, see list.

were abandoned because these numbers were low and variable across different cases. Nonetheless, it is possible that some double-labeled neurons may have been missed because the dense $\mathrm{CTb}$ reaction product found in some neurons may have obscured the TH staining in the same neurons.

There were not many usable "off-target" injection sites in the present study. In fact, the technical issue most often encountered was not of making injections outside the PVT but rather that the tracer did not diffuse out of the micropipette sufficiently to yield an injection site capable of producing retrograde labeling. A couple of injection sites in the paratenial nucleus immediately adjacent to the aPVT produced a large number of retrogradely labeled neurons in the prefrontal cortex but no labeling in the hypothalamus or the midbrain. It should also be pointed out that there was no evidence of double-labeled neurons in the VTA in the cases in which the CTb injection involved the medial most part of the mediodorsal nucleus. This indicates that the PVT and other nuclei immediately adjacent to the PVT do not receive any appreciable innervation from DA neurons in the VTA. Finally, the absence of double-labeled neurons in the VTA, which is known to provide a robust DA innervation of the habenula by way of the fasciculus retroflexus (Gruber et al., 2007), provides further reassurance that the labeling observed was not due to diffusion of CTb outside the PVT or from uptake by damaged fibers traveling through the PVT.

\section{DISCUSSION}

The main finding of the present study is that neurons that are located in the hypothalamus and periaqueductal gray provide the DA fibers to the PVT. Most of the TH/CTb double-labeled neurons were found in the A10vr, A11, A13, A15 DA cell groups of the hypothalamus and A10dc of the periaqueductal gray. In contrast, no evidence was found that the PVT receives projections from DA neurons in the ventral tegmental area (A10, excluding the A10vr and A10dc), substantia nigra (A9), and the retrorubral field (A8). While there are clear differences between rodents and primates in the distribution and density of DA fibers in the thalamus (García-Cabezas et al., 2009), the findings in the present study show that the origin of DA fibers in the dorsal midline thalamus is the same between these two species (SánchezGonzález et al., 2005).

Our findings along with the results of other tracing studies in the rat and primate are in stark contrast with another study reporting numerous double-labeled TH neurons in the VTA and retrorubral field following injections of the retrograde tracer Fluorogold in the PVT (Takada et al., 1990). It is likely that the false positives observed by the Takada et al. study may have occurred because Fluorogold was taken up by damaged DA fibers passing through the dorsal midline thalamus on their way to the habenular complex (Gruber et al., 2007). Labeling of fibers of passage is especially problematic when tracers are applied using pressure injections or when using fluorescent tracers like 


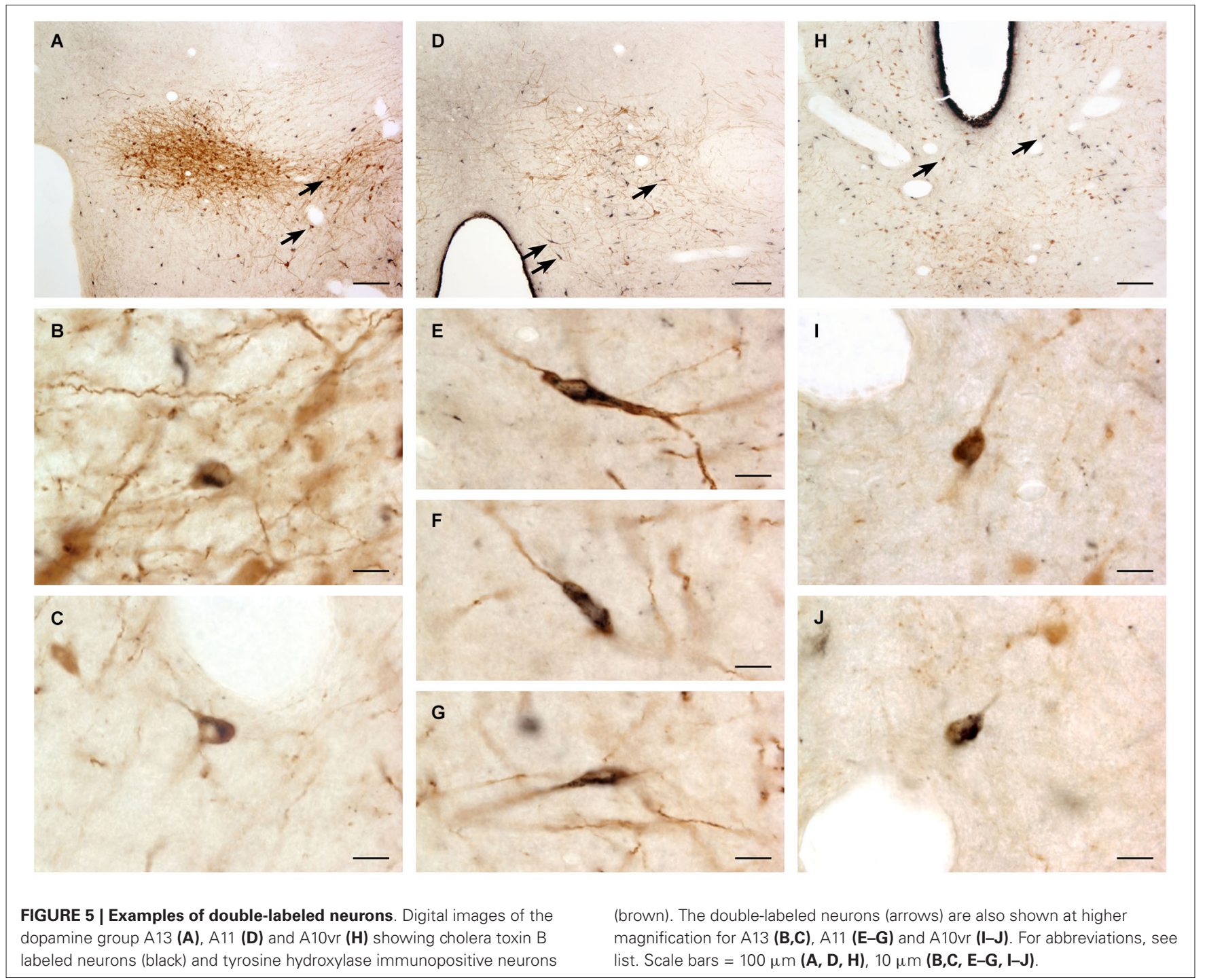

Fluorogold (Aschoff and Holländer, 1982; Dado et al., 1990; Schofield et al., 2007), as was the case with Takada et al. study (Takada et al., 1990). It is also possible that the misidentification of a significant DA projection from the VTA to the PVT may have been the result of large injections of retrograde tracers that involved parts of the mediodorsal nucleus, which has been shown to receive DA fibers from the VTA (Groenewegen, 1988). The lack of evidence for a DA projection from the VTA to the PVT is also in line with the tracing studies showing an absence of retrogradely labeled neurons in the VTA following injections of tracers in the PVT (Cornwall and Phillipson, 1988; Chen and Su, 1990; Li and Kirouac, 2012). Consequently, we conclude that the majority of evidence available indicates that the PVT does not receive an appreciable projection from DA neurons in the VTA.

What is the potential functional significance of DA innervation of the PVT which originates from neurons scattered in the hypothalamus? This is a question that can only be speculated at because of the paucity of information about the function of these DA neurons. One possibility is that this projection may be involved in arousal since a subpopulation of DA neurons in the hypothalamus was shown to be activated in rats that had explored an open field (A11 group) and after sleep deprivation (A11 and A13 groups) (Léger et al., 2010). While this has not been demonstrated, it is possible that the DA cell groups in the hypothalamus have functions related to DA cells in the VTA. As such, the release of DA along with other transmitters like orexins and cocaine- and amphetamine-related peptide (James et al., 2010; Matzeu et al., 2014) could act on the PVT to modulate reward and motivated behavior. In addition, the A13 DA cell group has been shown to project to the central nucleus of the amygdala and the periaqueductal gray matter (Eaton et al., 1994; Messanvi et al., 2013), two key areas involved in defensive behaviors (McNaughton and Corr, 2004). This suggests that the A13 DA group and the PVT may be part of a network involved in the modulation of defensive behaviors. Indeed, recent experimental evidence indicates that the PVT plays a role in fear, anxiety and avoidance. For instance, microinjections of excitatory neuropeptides called orexins in the PVT of rats were found to 
produce anxiety-like behaviors while blocking of orexin receptors had anxiolytic effects (Li et al., 2009, 2010a,b; Heydendael et al., 2011). In addition, microinjections of orexin antagonists in the PVT were shown to attenuate conditioned place avoidance to morphine withdrawal (Li et al., 2011) and lesions of the pPVT were reported to attenuate a conditioned fear response (Li et al., 2014). Numerous studies have also documented that neurons in the PVT are activated in animals exposed to a variety of stressful/aversive situations (Beck and Fibiger, 1995; Bhatnagar and Dallman, 1998; Bubser and Deutch, 1999; Timofeeva and Richard, 2001) and it is possible that DA signaling may be involved in the activation of the PVT following high levels of arousal. Finally, the A15 DA group has been shown in some species to be associated with neuroendocrine functions including seasonal inhibition of gonadotrophin-releasing hormone (Hileman and Jackson, 1999; Goodman et al., 2010). Consequently, the A15 cell group may influence the PVT in a way that helps coordinate arousal levels and behaviors with the hormonal status of an organism.

It is also interesting to note that the primary DA receptor found in the PVT is the D3 receptor where the expression of this receptor is high compared to many areas of the rat (Stanwood et al., 2000; Haight and Flagel, 2014) and human brain (Rieck et al., 2004). The D3 receptor is of clinical interest because it has been linked to the regulation of the cognitive symptoms of schizophrenia and the motivation to seek drugs in addicted individuals (Gross et al., 2013; Micheli and Heidbreder, 2013). While the potential therapeutic effects of the D3 antagonists have been shown to be mediated by D3 receptors in the nucleus accumbens (Gross et al., 2013; Micheli and Heidbreder, 2013), it is also possible that some of these effects could be mediated by D3 receptors in the PVT. For instance, the PVT has been shown to modulate DA release in the nucleus accumbens (Jones et al., 1989; Parsons et al., 2007; Choi et al., 2012) and D3 antagonists could act at the PVT to down-regulate the enhanced DA release in the nucleus accumbens associated with schizophrenia and drug seeking. In line with that hypothesis, lesions of the PVT were shown to attenuate the conditioned aspects of behavioral sensitization to cocaine possibly through a D3 mediated mechanism in the PVT (Deutch et al., 1998; Young and Deutch, 1998). Blocking of D3 receptors has also been shown to attenuate fear expression in conditioned rats (Swain et al., 2008) and the PVT represents a potential site for this effect.

In summary, the present tracing study shows that DA innervation of the PVT originates from the hypothalamus (A10vr, A11, A13, A15) and periaqueductal gray (A10dc) and not from the midbrain's A8, A9 and A10 DA cell groups. The type of signal carried by these fibers and functional consequence of DA release in the PVT are not known but the PVT represents a unique site for D3 receptor antagonists to exert some of their pharmacological effects. Future research may identify more specific effects of DA on PVT mediated behaviors.

\section{ACKNOWLEDGMENTS}

This work was supported by the Canadian Institute of Health Research (CIHR; MOP89758 to Gilbert J. Kirouac); the National Natural Science Foundation of China (No. 31200772) and
Research fund from the Doctoral Program of Higher Education of China (No.20132104110021).

\section{REFERENCES}

Aschoff, A., and Holländer, H. (1982). Fluorescent compounds as retrograde tracers compared with horseradish peroxidase (HRP). I. A parametric study in the central visual system of the albino rat. J. Neurosci. Methods 6, 179-197. doi: 10. 1016/0165-0270(82)90083-8

Beck, C. H., and Fibiger, H. C. (1995). Conditioned fear-induced changes in behavior and in the expression of the immediate early gene c-fos: with and without diazepam pretreatment. J. Neurosci. 15, 709-720.

Berendse, H. W., Galis-De Graaf, Y., and Groenewegen, H. J. (1992). Topographical organization and relationship with ventral striatal compartments of prefrontal corticostriatal projections in the rat. J. Comp. Neurol. 316, 314-347. doi: 10. 1002/cne.903160305

Berendse, H. W., and Groenewegen, H. J. (1990). Organization of the thalamostriatal projections in the rat, with special emphasis on the ventral striatum. J. Comp. Neurol. 299, 187-228. doi: 10.1002/cne.902990206

Bhatnagar, S., and Dallman, M. (1998). Neuroanatomical basis for facilitation of hypothalamic-pituitary-adrenal responses to a novel stressor after chronic stress. Neuroscience 84, 1025-1039. doi: 10.1016/s0306-4522(97)00577-0

Brog, J. S., Salyapongse, A., Deutch, A. Y., and Zahm, D. S. (1993). The patterns of afferent innervation of the core and shell in the "accumbens" part of the rat ventral striatum: immunohistochemical detection of retrogradely transported fluoro-gold. J. Comp. Neurol. 338, 255-278. doi: 10.1002/cne.903380209

Brown, E. E., Robertson, G. S., and Fibiger, H. C. (1992). Evidence for conditional neuronal activation following exposure to a cocaine-paired environment: role of forebrain limbic structures. J. Neurosci. 12, 4112-4121.

Browning, J. R., Jansen, H. T., and Sorg, B. A. (2014). Inactivation of the paraventricular thalamus abolishes the expression of cocaine conditioned place preference in rats. Drug Alcohol Depend. 134, 387-390. doi: 10.1016/j.drugalcdep.2013. 09.021

Bubser, M., and Deutch, A. Y. (1999). Stress induces Fos expression in neurons of the thalamic paraventricular nucleus that innervate limbic forebrain sites. Synapse 32, 13-22. doi: 10.1002/(sici) 1098-2396(199904)32:1<13::aid-syn2>3. $0 . \mathrm{co} ; 2-\mathrm{r}$

Chen, S., and Su, H. S. (1990). Afferent connections of the thalamic paraventricular and parataenial nuclei in the rat-a retrograde tracing study with iontophoretic application of Fluoro-Gold. Brain Res. 522, 1-6. doi: 10.1016/00068993(90)91570-7

Choi, D. L., Davis, J. F., Magrisso, I. J., Fitzgerald, M. E., Lipton, J. W., and Benoit, S. C. (2012). Orexin signaling in the paraventricular thalamic nucleus modulates mesolimbic dopamine and hedonic feeding in the rat. Neuroscience 210, 243 248. doi: 10.1016/j.neuroscience.2012.02.036

Cornwall, J., and Phillipson, O. T. (1988). Afferent projections to the dorsal thalamus of the rat as shown by retrograde lectin transport-I. The mediodorsal nucleus. Neuroscience 24, 1035-1049. doi: 10.1016/0306-4522(88)90085-1

Dado, R. J., Burstein, R., Cliffer, K. D., and Giesler, G. J. Jr. (1990). Evidence that Fluoro-Gold can be transported avidly through fibers of passage. Brain Res. 533, 329-333. doi: 10.1016/0006-8993(90)91358-n

Dahlstroem, A., and Fuxe, K. (1964). Evidence for the existence of monoaminecontaining neurons in the central nervous system. I. Demostration of monoamines in the cell bodies of brain stem neurons. Acta Physiol. Scand. Suppl. 232, 1-55.

Dayas, C. V., Mcgranahan, T. M., Martin-Fardon, R., and Weiss, F. (2008). Stimuli linked to ethanol availability activate hypothalamic CART and orexin neurons in a reinstatement model of relapse. Biol. Psychiatry 63, 152-157. doi: 10.1016/j. biopsych.2007.02.002

Deutch, A. Y., Bubser, M., and Young, C. D. (1998). Psychostimulant-induced Fos protein expression in the thalamic paraventricular nucleus. J. Neurosci. 18, 10680-10687.

Eaton, M. J., Wagner, C. K., Moore, K. E., and Lookingland, K. J. (1994). Neurochemical identification of A13 dopaminergic neuronal projections from the medial zona incerta to the horizontal limb of the diagonal band of Broca and the central nucleus of the amygdala. Brain Res. 659, 201-207. doi: 10.1016/00068993(94)90879-6

Flagel, S. B., Cameron, C. M., Pickup, K. N., Watson, S. J., Akil, H., and Robinson, T. E. (2011). A food predictive cue must be attributed with incentive salience for 
it to induce c-fos mRNA expression in cortico-striatal-thalamic brain regions. Neuroscience 196, 80-96. doi: 10.1016/j.neuroscience.2011.09.004

Franklin, T. R., and Druhan, J. P. (2000). Expression of Fos-related antigens in the nucleus accumbens and associated regions following exposure to a cocainepaired environment. Eur. J. Neurosci. 12, 2097-2106. doi: 10.1046/j.1460-9568. 2000.00071.x

García-Cabezas, M. A., Martínez-Sánchez, P., Sánchez-González, M. A., Garzón, M., and Cavada, C. (2009). Dopamine innervation in the thalamus: monkey versus rat. Cereb Cortex 19, 424-434. doi: 10.1093/cercor/bhn093

Goodman, R. L., Jansen, H. T., Billings, H. J., Coolen, L. M., and Lehman, M. N. (2010). Neural systems mediating seasonal breeding in the ewe. J. Neuroendocrinol. 22, 674-681. doi: 10.1111/j.1365-2826.2010.02014.x

Groenewegen, H. J. (1988). Organization of the afferent connections of the mediodorsal thalamic nucleus in the rat, related to the mediodorsal-prefrontal topography. Neuroscience 24, 379-431. doi: 10.1016/0306-4522(88)90339-9

Groenewegen, H. J., and Berendse, H. W. (1994). The specificity of the 'nonspecific' midline and intralaminar thalamic nuclei. Trends Neurosci. 17, 52-57. doi: 10 1016/0166-2236(94)90074-4

Groenewegen, H. J., Vermeulen-Van Der Zee, E., te Kortschot, A., and Witter, M. P. (1987). Organization of the projections from the subiculum to the ventral striatum in the rat. A study using anterograde transport of Phaseolus vulgaris leucoagglutinin. Neuroscience 23, 103-120. doi: 10.1016/0306-4522(87) 90275-2

Gross, G., Wicke, K., and Drescher, K. U. (2013). Dopamine D(3) receptor antagonism-still a therapeutic option for the treatment of schizophrenia. Naunyn Schmiedebergs Arch. Pharmacol. 386, 155-166. doi: 10.1007/s00210012-0806-3

Gruber, C., Kahl, A., Lebenheim, L., Kowski, A., Dittgen, A., and Veh, R. W. (2007). Dopaminergic projections from the VTA substantially contribute to the mesohabenular pathway in the rat. Neurosci. Lett. 427, 165-170. doi: 10.1016/j. neulet.2007.09.016

Haight, J. L., and Flagel, S. B. (2014). A potential role for the paraventricular nucleus of the thalamus in mediating individual variation in Pavlovian conditioned responses. Front. Behav. Neurosci. 8:79. doi: 10.3389/fnbeh.2014.00079

Hamlin, A. S., Clemens, K. J., Choi, E. A., and Mcnally, G. P. (2009). Paraventricular thalamus mediates context-induced reinstatement (renewal) of extinguished reward seeking. Eur. J. Neurosci. 29, 802-812. doi: 10.1111/j.1460-9568.2009. 06623.x

Heydendael, W., Sharma, K., Iyer, V., Luz, S., Piel, D., Beck, S., et al. (2011). Orexins/hypocretins act in the posterior paraventricular thalamic nucleus during repeated stress to regulate facilitation to novel stress. Endocrinology 152, 47384752. doi: 10.1210/en.2011-1652

Hileman, S. M., and Jackson, G. L. (1999). Regulation of gonadotrophin-releasing hormone secretion by testosterone in male sheep. J. Reprod. Fertil. Suppl. 54, 231-242.

Hökfelt, T., Smith, C. B., Norell, G., Peters, A., Crane, A., Goldstein, M., et al. (1984). Attempts to combine 2-deoxyglucose autoradiography and tyrosine hydroxylase immunohistochemistry. Neuroscience 13, 495-512. doi: 10. 1016/0306-4522(84)90244-6

Humphries, M. D., and Prescott, T. J. (2010). The ventral basal ganglia, a selection mechanism at the crossroads of space, strategy and reward. Prog. Neurobiol. 90, 385-417. doi: 10.1016/j.pneurobio.2009.11.003

Igelstrom, K. M., Herbison, A. E., and Hyland, B. I. (2010). Enhanced c-Fos expression in superior colliculus, paraventricular thalamus and septum during learning of cue-reward association. Neuroscience 168, 706-714. doi: 10.1016/j. neuroscience.2010.04.018

Ikemoto, S. (2007). Dopamine reward circuitry: two projection systems from the ventral midbrain to the nucleus accumbens-olfactory tubercle complex. Brain Res. Rev. 56, 27-78. doi: 10.1016/j.brainresrev.2007.05.004

Ikemoto, S., and Panksepp, J. (1999). The role of nucleus accumbens dopamine in motivated behavior: a unifying interpretation with special reference to reward-seeking. Brain Res. Brain Res. Rev. 31, 6-41. doi: 10.1016/s0165-0173(99) 00023-5

James, M. H., Charnley, J. L., Flynn, J. R., Smith, D. W., and Dayas, C. V. (2011). Propensity to 'relapse' following exposure to cocaine cues is associated with the recruitment of specific thalamic and epithalamic nuclei. Neuroscience 199, 235242. doi: 10.1016/j.neuroscience.2011.09.047

James, M. H., Charnley, J. L., Jones, E., Levi, E. M., Yeoh, J. W., Flynn, J. R., et al. (2010). Cocaine- and amphetamine-regulated transcript (CART) signaling within the paraventricular thalamus modulates cocaine-seeking behaviour. PLoS One 5:e12980. doi: 10.1371/journal.pone.0012980

James, M. H., and Dayas, C. V. (2013). What about me...? The PVT: a role for the paraventricular thalamus (PVT) in drug-seeking behavior. Front. Behav. Neurosci. 7:18. doi: 10.3389/fnbeh.2013.00018

Jones, M. W., Kilpatrick, I. C., and Phillipson, O. T. (1989). Regulation of dopamine function in the nucleus accumbens of the rat by the thalamic paraventricular nucleus and adjacent midline nuclei. Exp. Brain Res. 76, 572-580. doi: 10. 1007/bf00248914

Léger, L., Sapin, E., Goutagny, R., Peyron, C., Salvert, D., Fort, P., et al. (2010). Dopaminergic neurons expressing Fos during waking and paradoxical sleep in the rat. J. Chem. Neuroanat. 39, 262-271. doi: 10.1016/j.jchemneu.2010.03.001

Li, Y., Dong, X., Li, S., and Kirouac, G. J. (2014). Lesions of the posterior paraventricular nucleus of the thalamus attenuate fear expression. Front. Behav. Neurosci. 8:94. doi: 10.3389/fnbeh.2014.00094

Li, S., and Kirouac, G. J. (2008). Projections from the paraventricular nucleus of the thalamus to the forebrain, with special emphasis on the extended amygdala. J. Comp. Neurol. 506, 263-287. doi: 10.1002/cne.21741

Li, S., and Kirouac, G. J. (2012). Sources of inputs to the anterior and posterior aspects of the paraventricular nucleus of the thalamus. Brain Struct. Funct. 217, 257-273. doi: 10.1007/s00429-011-0360-7

Li, Y., Li, S., Sui, N., and Kirouac, G. J. (2009). Orexin-A acts on the paraventricular nucleus of the midline thalamus to inhibit locomotor activity in rats. Pharmacol. Biochem. Behav. 93, 506-514. doi: 10.1016/j.pbb.2009.06.017

Li, Y., Li, S., Wei, C., Wang, H., Sui, N., and Kirouac, G. J. (2010a). Changes in emotional behavior produced by orexin microinjections in the paraventricular nucleus of the thalamus. Pharmacol. Biochem. Behav. 95, 121-128. doi: 10. 1016/j.pbb.2009.12.016

Li, Y., Li, S., Wei, C., Wang, H., Sui, N., and Kirouac, G. J. (2010b). Orexins in the paraventricular nucleus of the thalamus mediate anxiety-like responses in rats. Psychopharmacology (Berl) 212, 251-265. doi: 10.1007/s00213-010-1948-y

Li, Y., Wang, H., Qi, K., Chen, X., Li, S., Sui, N., et al. (2011). Orexins in the midline thalamus are involved in the expression of conditioned place aversion to morphine withdrawal. Physiol. Behav. 102, 42-50. doi: 10.1016/j.physbeh.2010. 10.006

Lindvall, O., Björklund, A., and Skagerberg, G. (1983). Dopamine-containing neurons in the spinal cord: anatomy and some functional aspects. Ann. Neurol. 14, 255-260. doi: 10.1002/ana.410140302

Marchant, N. J., Furlong, T. M., and Mcnally, G. P. (2010). Medial dorsal hypothalamus mediates the inhibition of reward seeking after extinction. J. Neurosci. 30, 14102-14115. doi: 10.1523/jneurosci.4079-10.2010

Martin-Fardon, R., and Boutrel, B. (2012). Orexin/hypocretin (Orx/Hcrt) transmission and drug-seeking behavior: is the paraventricular nucleus of the thalamus (PVT) part of the drug seeking circuitry? Front. Behav. Neurosci. 6:75. doi: 10.3389/fnbeh.2012.00075

Matzeu, A., Zamora-Martinez, E. R., and Martin-Fardon, R. (2014). The paraventricular nucleus of the thalamus is recruited by both natural rewards and drugs of abuse: recent evidence of a pivotal role for orexin/hypocretin signaling in this thalamic nucleus in drug-seeking behavior. Front. Behav. Neurosci. 8:117. doi: 10.3389/fnbeh.2014.00117

McNaughton, N., and Corr, P. J. (2004). A two-dimensional neuropsychology of defense: fear/anxiety and defensive distance. Neurosci. Biobehav. Rev. 28, 285305. doi: 10.1016/j.neubiorev.2004.03.005

Messanvi, F., Eggens-Meijer, E., Roozendaal, B., and van Der Want, J. J. (2013). A discrete dopaminergic projection from the incertohypothalamic A13 cell group to the dorsolateral periaqueductal gray in rat. Front. Neuroanat. 7:41. doi: 10. 3389/fnana.2013.00041

Micheli, F., and Heidbreder, C. (2013). Dopamine D3 receptor antagonists: a patent review (2007-2012). Expert Opin. Ther. Pat. 23, 363-381. doi: 10. 1517/13543776.2013.757593

Nicola, S. M. (2007). The nucleus accumbens as part of a basal ganglia action selection circuit. Psychopharmacology (Berl) 191, 521-550. doi: 10.1007/s00213006-0510-4

Otake, K., and Ruggiero, D. A. (1995). Monoamines and nitric oxide are employed by afferents engaged in midline thalamic regulation. J. Neurosci. 15, 1891-1911.

Parsons, M. P., Li, S., and Kirouac, G. J. (2007). Functional and anatomical connection between the paraventricular nucleus of the thalamus and dopamine fibers of the nucleus accumbens. J. Comp. Neurol. 500, 1050-1063. doi: 10. 1002/cne.21224 
Paxinos, G., and Watson, C. (2009). The Rat Brain in Stereotaxic Coordinates: Sixth Edition. San Diego: Elsevier Academic Press.

Pennartz, C. M., Groenewegen, H. J., and Lopes Da Silva, F. H. (1994). The nucleus accumbens as a complex of functionally distinct neuronal ensembles: an integration of behavioural, electrophysiological and anatomical data. Prog. Neurobiol. 42, 719-761. doi: 10.1016/0301-0082(94)90025-6

Perry, C. J., and Mcnally, G. P. (2013). A role for the ventral pallidum in contextinduced and primed reinstatement of alcohol seeking. Eur. J. Neurosci. 38, 27622773. doi: 10.1111/ejn.12283

Rieck, R. W., Ansari, M. S., Whetsell, W. O. Jr., and Deutch, A. Y., and Kessler, R. M. (2004). Distribution of dopamine D2-like receptors in the human thalamus: autoradiographic and PET studies. Neuropsychopharmacology 29, 362-372. doi: 10.1038/sj.npp.1300336

Salamone, J. D., Correa, M., Mingote, S. M., and Weber, S. M. (2005). Beyond the reward hypothesis: alternative functions of nucleus accumbens dopamine. Curr. Opin. Pharmacol. 5, 34-41. doi: 10.1016/j.coph.2004.09.004

Sánchez-González, M. A., García-Cabezas, M. A., Rico, B., and Cavada, C. (2005). The primate thalamus is a key target for brain dopamine. J. Neurosci. 25, 60766083. doi: 10.1523/jneurosci.0968-05.2005

Schofield, B. R., Schofield, R. M., Sorensen, K. A., and Motts, S. D. (2007). On the use of retrograde tracers for identification of axon collaterals with multiple fluorescent retrograde tracers. Neuroscience 146, 773-783. doi: 10 1016/j.neuroscience.2007.02.026

Schultz, W. (2000). Multiple reward signals in the brain. Nat. Rev. Neurosci. 1, 199207. doi: $10.1038 / 35044563$

Stanwood, G. D., Artymyshyn, R. P., Kung, M. P., Kung, H. F., Lucki, I., and Mcgonigle, P. (2000). Quantitative autoradiographic mapping of rat brain dopamine D3 binding with [(125)I]7-OH-PIPAT: evidence for the presence of D3 receptors on dopaminergic and nondopaminergic cell bodies and terminals. J. Pharmacol. Exp. Ther. 295, 1223-1231.

Swain, S. N., Beuk, J., Heidbreder, C. A., and Beninger, R. J. (2008). Role of dopamine D3 receptors in the expression of conditioned fear in rats. Eur. J. Pharmacol. 579, 167-176. doi: 10.1016/j.ejphar.2007.10.011

Takada, M., Campbell, K. J., Moriizumi, T., and Hattori, T. (1990). On the origin of the dopaminergic innervation of the paraventricular thalamic nucleus. Neurosci. Lett. 115, 33-36. doi: 10.1016/0304-3940(90)90513-9

Timofeeva, E., and Richard, D. (2001). Activation of the central nervous system in obese Zucker rats during food deprivation. J. Comp. Neurol. 441, 71-89. doi: 10 $1002 /$ cne. 1398
Van der Werf, Y. D., Witter, M. P., and Groenewegen, H. J. (2002). The intralaminar and midline nuclei of the thalamus. Anatomical and functional evidence for participation in processes of arousal and awareness. Brain Res. Brain Res. Rev. 39, 107-140. doi: 10.1016/s0165-0173(02)00181-9

Vertes, R. P., and Hoover, W. B. (2008). Projections of the paraventricular and paratenial nuclei of the dorsal midline thalamus in the rat. J. Comp. Neurol. 508, 212-237. doi: 10.1002/cne.21679

Wedzony, K., Koros, E., Czyrak, A., Chocyk, A., Czepiel, K., Fijal, K., et al. (2003). Different pattern of brain c-Fos expression following re-exposure to ethanol or sucrose self-administration environment. Naunyn Schmiedebergs Arch. Pharmacol. 368, 331-341. doi: 10.1007/s00210-003-0811-7

Wright, C. I., Beijer, A. V., and Groenewegen, H. J. (1996). Basal amygdaloid complex afferents to the rat nucleus accumbens are compartmentally organized. J. Neurosci. 16, 1877-1893.

Wright, C. I., and Groenewegen, H. J. (1995). Patterns of convergence and segregation in the medial nucleus accumbens of the rat: relationships of prefrontal cortical, midline thalamic and basal amygdaloid afferents. J. Comp. Neurol. 361, 383-403. doi: 10.1002/cne.903610304

Young, C. D., and Deutch, A. Y. (1998). The effects of thalamic paraventricular nucleus lesions on cocaine-induced locomotor activity and sensitization. Pharmacol. Biochem. Behav. 60, 753-758. doi: 10.1016/s0091-3057(98) 00051-3

Conflict of Interest Statement: The authors declare that the research was conducted in the absence of any commercial or financial relationships that could be construed as a potential conflict of interest.

Received: 27 August 2014; accepted: 03 November 2014; published online: 20 November 2014

Citation: Li S, Shi Y and Kirouac GJ (2014) The hypothalamus and periaqueductal gray are the sources of dopamine fibers in the paraventricular nucleus of the thalamus in the rat. Front. Neuroanat. 8:136. doi: 10.3389/fnana.2014.00136

This article was submitted to the journal Frontiers in Neuroanatomy.

Copyright (c) $2014 \mathrm{Li}$, Shi and Kirouac. This is an open-access article distributed under the terms of the Creative Commons Attribution License (CC BY). The use, distribution and reproduction in other forums is permitted, provided the original author(s) or licensor are credited and that the original publication in this journal is cited, in accordance with accepted academic practice. No use, distribution or reproduction is permitted which does not comply with these terms. 